\title{
Variação sazonal na morfologia dos ductos eferentes distais em codorna doméstica mantida em cativeiro experimental
}

\author{
Morphologic seasonal variability on the distal efferent ducts of domestic quail under experimental \\ captive breeding
}

\author{
Antonio Marcos Orsi ${ }^{\mathrm{I}}$ Raquel Fantin Domeniconi ${ }^{\mathrm{I}^{*}}$ Selma Maria Michelin Matheus ${ }^{\mathrm{II}}$ \\ Karina Simões ${ }^{\mathrm{III}}$ Célia Cristina Leme Beu ${ }^{\mathrm{IV}}$ Maíra Aparecida Stefanini ${ }^{\mathrm{V}}$
}

\section{RESUMO}

\begin{abstract}
Neste estudo diferenças expressivas foram observadas na estrutura dos ductos eferentes distais (DED) de codorna doméstica Coturnix coturnix, da variedade italiana, mantida em cativeiro experimental durante dois anos, durante as quatro estações do ano. A variabilidade morfológica dos DED foi mais marcante na primavera e no outono, eqüivalendo às fases ativa $e$ quiescente do ciclo reprodutivo anual (ciclo testicular) nesta ave. Nessas fases do ciclo, diferenças significativas foram observadas na ultraestrutura das células principais $(P)$ e ciliadas $(C)$ do epitélio de revestimento tubular e nos calibres tubulares. Estes tiveram valores médios maiores na primavera, com valores similares no verão e no inverno, e valores médios menores observados no outono. Na primavera, no citoplasma apical de células $P$, notou-se maior complexidade organelar, inferindo-se a ocorrência de processos endocitóticos ativos. A quiescência outonal caracterizou-se por redução do calibre tubular dos DED, luz tubular vazia de espermatozóides, degenerações de organelas citoplasmáticas e "debridamentos" citoplasmáticos apicais em células $P$ e $C$. No inverno e verão, correspondentes às fases recrudescente e regressiva, respectivamente, do ciclo testicular nesta espécie, os dados obtidos foram, de modo geral, similares aos observados na primavera.
\end{abstract}

Palavras-chave: ductos eferentes distais, morfologia, dados morfométricos, codorna doméstica.

\section{ABSTRACT}

Some expressive differences were noted on the distal efferent ducts (DED) morphology in domestic quail of the Italian variety along the year. The birds were maintained on experimental captive breeding along two consecutive years, before the morphologic studies. Morphologic differences on the DED had been more evident in spring and autumn respectively, the active and quiescent phases of the annual testis cycle. Variability more expressive was noted among the principal (P) and ciliated (C) epithelial cells and in tubular diameters of DED, during the two focused seasons. Spring features of DED were marked by relative enlargement of the passageways, with similar results in summer and winter, and characteristic organelle development on the apical cytoplasm of $P$ cells, allowing to conclude presence of active process of endocytosis. Autumn quiescence was marked by an enfolding pattern of all the tubular passageways, lacking of spermatozoa and small amount of heterogeneous material inside their luminal compartments, followed by presence of ultrastructural degenerative features in apical cytoplasm of $P$ cells and $C$ cells in DED passageways. Tubular features verified in DED during winter and summer were minor and similar to those described in spring. Summer and winter were respectively considered the recrudescent and regressive phases of the testis cycle in these species, based on the spermatogenesis cycle analysed in all the seasons of the year as well as on the base the morphologic features here found.

Key words: efferent distal ducts, morphology, morphometric data, Italian domestic quail.

\section{INTRODUÇÃO}

Os ductos eferentes de aves têm sido morfologicamente divididos em dois segmentos

\footnotetext{
'Departamento de Anatomia, Universidade Estadual Paulista (UNESP), Botucatu, SP. Área de Anatomia da Faculdade de Medicina e Enfermagem (UNIMAR), Marília, SP, Brasil.

II Departamento de Anatomia, UNESP, CP 510, 18618-000, Botucatu, SP, Brasil. Email: rdomeniconi@yahoo.com.br. *Autor para correspondência. (14)3811-6040/3811-6099.

IIIÁrea de Anatomia da Universidade de Rio Preto (UNIRP), São José do Rio Preto, SP, Brasil.

Iv Departamento de Morfofisiologia, Universidade do Oeste do Paraná (UNIOESTE), Cascavel, PR, Brasil.

${ }^{\vee}$ Departamento de Morfologia e Patologia, Universidade Federal de São Carlos (UFSCar), São Carlos, SP, Brasil.
} 
distintos e contínuos da via espermática extratesticular: os ductos eferentes proximais e os ductos eferentes distais (AIRE, 1979; 1980; STEFANINI et al., 1999a; OZEGBE et al., 2006). Nos ductos eferentes da via espermática de aves, inclusive na própria codorna doméstica, especialmente nos ductos eferentes proximais (DEP), foram caracterizados, ao nível ultraestrutural, processos ativos de pinocitose (endocitose de fase fluida) e de fagocitose (endocitose por adsorsão) presentes, principalmente, na margem adluminal do citoplasma das células principais (P) do epitélio de revestimento dos DEP (STEFANINI et al.,1999a;b; OZEGBE et al., 2006 ; ORSI et al., 2007).

Processos similares de internalização citoplasmática de fluidos (pinocitose) e de solutos (fagocitose) foram revistos na função celular geral das células de Sertoli (CLERMONT, 1993). Anteriormente, nas células $\mathrm{P}$ da rede testicular (RT) de rato albino, observouse uma internalização marcante de traçadores adsorptivos, carreados pelas vesículas pequenas e não revestidas em direção à membrana plasmática lateral de células da RT (MORALES et al., 1984). Verificou-se, também, endocitose de transferrina e de outras proteínas nas células epiteliais da RT e dos ductos eferentes de alguns mamíferos (HERMO et al., 1994). Confirmou-se, assim, a ocorrência de endocitose adsorptiva, e reforçou-se o conceito da endocitose de fase fluida, denominadas, respectivamente, de fagocitose e de pinocitose (CLERMONT, 1993).

Com base nessas informações, e na verificação de variabilidade sazonal na morfologia testicular (ORSI et al., 2005), acompanhadas de variações sazonais na morfologia e histofisiologia da RE e DEP de codorna doméstica (ORSI et al., 2007), considerou-se neste estudo a análise de características morfológicas dos DED desta espécie, mantida em cativeiro experimental, acompanhando os aspectos sazonais do ciclo testicular anual (ORSI et al., 2005). Nesse ciclo, verificou-se um ritmo espermatocitogenético circanual, presente na codorna de variedade italiana, havendo maior atividade gonadal na primavera e quiescência curta de atividade espermatogenética entre meados de março e meados de abril.

Portanto, neste estudo, apresenta-se a morfologia ultra-estrutural e algumas considerações sobre a histofisiologia dos DED na codorna da variedade italiana, mantida em cativeiro experimental durante dois anos. A Coturnix coturnix é uma pequena ave poedeira e de corte que tem apresentado interesse zootécnico, e também tem tido uso experimental em Biociências.

\section{MATERIAL E MÉTODOS}

Codornas (Coturnix coturnix) da variedade italiana ficaram confinadas em criatório de pesquisa,junto à Fazenda Experimental “Edgardia”, da Universidade Estadual Paulista, em Botucatu, durante 24 meses consecutivos, sendo um total de 30 machos sexualmente maduros. As aves permaneceram no cativeiro experimental, recebendo dieta sólida normal para aves (Purina, Brasil) e água, administradas ad libitum e sob condições de iluminação predominantemente natural. Logo, foram submetidas a aproximadamente 12 horas de luz e 12 horas de ausência de luz, permanecendo separadas, em gaiolas vazadas de criatório, de plantéis similares de fêmeas da mesma espécie e variedade, igualmente confinadas. Portanto, as aves de ambos os sexos ficaram em contato visual e sonoro, naquele período, porém, sem ocorrência de acasalamento.

Posteriormente, os machos foram transportados em grupos de seis codornas, durante os meses mais expressivos de verão (janeiro e meados de fevereiro), outono (meados de março e abril), inverno (junho e meados de julho) e primavera (meados de outubro e primeira quinzena de novembro) para os laboratórios de Anatomia e Morfologia Microscópica, do Instituto de Biociências, da UNESP, em Botucatu, onde se procedeu a eutanásia das aves por meio de saturação anestésica com a mistura de XylazinaKetamina(EUA).

A seguir, foram feitas as coletas bilaterais dos testículos e da região epididimária (RE) das codornas. Fragmentos dos materiais coletados foram fixados nos fixadores histológicos de formalina tamponada, em tampão fosfato, pH 7,2, 0,1M, líquido de Bouin e soluções de Karnovsky e de McDowell. Os dois primeiros fixadores histológicos foram utilizados para os fragmentos de tecidos destinados para estudos de microscopia de luz de materiais processados em paraplast (Oxford Labware, EUA). Os dois últimos fixadores foram usados para materiais destinados à rotina de historesina (Historesin, Leica, Alemanha), sendo o material fixado em Karnovsky destinado para a rotina de microscopia eletrônica de transmissão (MET). Os estudos de MET foram feitos em materiais obtidos de coletas, bilaterais, das regiões epididimárias de outras seis aves, sendo duas no outono, duas na primavera, uma no verão e uma no inverno,.

As rotinas de microscopia de luz foram as habituais, com inclusões dos materiais em paraplast (EUA) e/ou em historesin (Alemanha), microtomia (cortes de 1,5 a $5 \mu \mathrm{m}$ ) e colorações com HE, tricrômico de Masson-Goldner, PAS/H, hematoxilina/floxina e solução de azul de toluidina a 0,5\%, destinando esses materiais para estudos em microscópio de pesquisa Olympus BX-40 (Olympus, Japão). Estudos histomorfométricos dos DED, nas quatro estações do 
ano, foram realizados com a utilização de sistema integrado de análise de imagens ["microscópio Olympus BX-40 + Software System (EUA) da Media Cybernetics"].

As análises histomorfométricas foram feitas a partir dos dados quantitativos, visando-se obter os valores médios de alturas epiteliais e dos diâmetros tubulares e luminais dos DED. Para as mensurações destes parâmetros, foram utilizadas três lâminas de cada animal, contendo seis cortes histológicos com quatro medidas por corte. Os resultados foram agrupados por estações do ano e tratados estatisticamente por métodos paramétricos, ou seja, com cálculos dos valores de médias aritméticas; desvios-padrão e análises de variância (MORRISON, 1976).

Nos fragmentos dos tecidos para estudos em microscopia eletrônica de transmissão dos DED, foi feita a pós-fixação tissular em tetróxido de ósmio a $1 \%$ em tampão fosfato de sódio $\mathrm{pH} 7,2,0,1 \mathrm{M}$, durante uma hora a $4^{\circ} \mathrm{C}$. Os fragmentos teciduais foram desidratados em série crescente de acetona, incluídos em Araldite (Merck, Alemanha), e submetidos à ultramicrotomia. Os cortes ultrafinos $(80 \mathrm{~nm})$ obtidos foram montados em grades de cobre, contrastados com acetato de uranila e citrato de chumbo e analisados e documentados fotograficamente em ME Philips CEM 100 (Philips, Holanda).

\section{RESULTADOS}

Os valores médios dos diâmetros tubular e luminal dos ductos eferentes distais (DED) e da altura do seu epitélio de revestimento em codorna doméstica da variedade italiana, verificados em todas as estações do ano, foram ilustrados na figura 1 . Na ultra-estrutura epitelial dos DED, foram vizualizadas, com disposição alternada, células ciliadas (C) dotadas de longos cinetocílios intraluminais, ancorados em corpúsculos basais no citoplasma apical, e células principais (P), cuja margem apical é dotada de microvilos curtos (Figura 2a). A eletrodensidade citoplasmática das células ciliadas (C), no epitélio tubular, mostrou-se homogênea e as mitocôndrias foram as organelas predominantes aos níveis do citoplasma basal e apical das células P e $\mathrm{C}$, respectivamente. $\mathrm{O}$ citoplasma apical das células $\mathrm{P}$ mostrou cavéolas presentes junto à membrana plasmática apical, sendo acompanhadas de vesículas apicais claras e de lisossomos, havendo também poucas lamelas do RE-granular (Figura 2b).

No citoplasma supranuclear das células C, no epitélio de revestimento dos DED no verão, evidenciaram-se formações tubulares-canaliculares do "sistema T" apical e formações lamelares e vesiculares do retículo endoplasmático (RE) granular, havendo polissomos e vesículas associadas, com diferentes dimensões e conteúdos, e lisossomos. Nas membranas plasmáticas laterais, foram vizualizadas vesículas revestidas adjacentes e houve reforços apicais presentes entre as membranas contíguas feitos por junções íntimas (Figura 3a). O citoplasma supranuclear de células $\mathrm{P}$ mostrou, nos domínios do citoplasma supranuclear e apical, mitocôndrias, poucos lisossomos, lamelas do RE, um pequeno aparelho de Golgi, bem como polissomos associados ao RE-granular e a vesículas variadas inter-relacionadas ao complexo do Golgi-RE (Figura 3b).

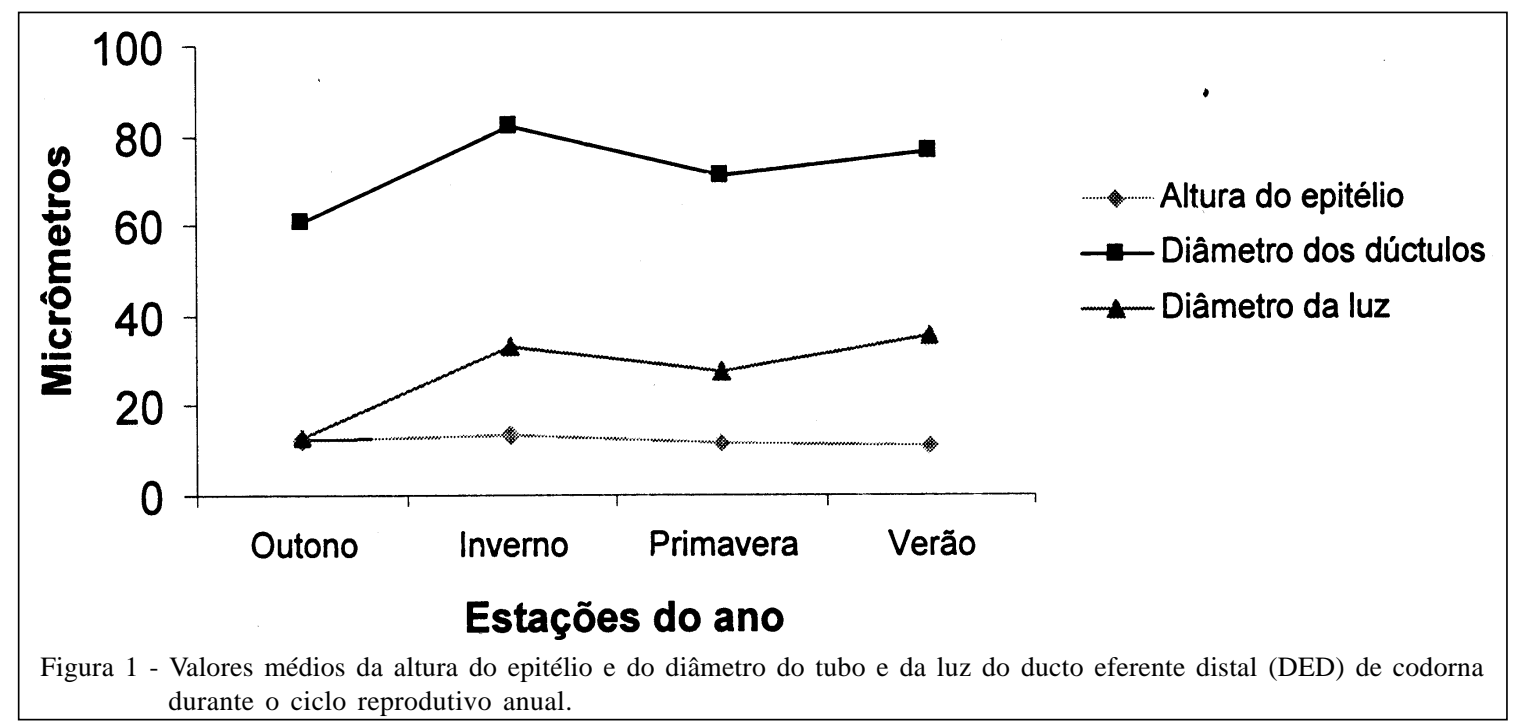

Ciência Rural, v.38, n.6, set, 2008. 


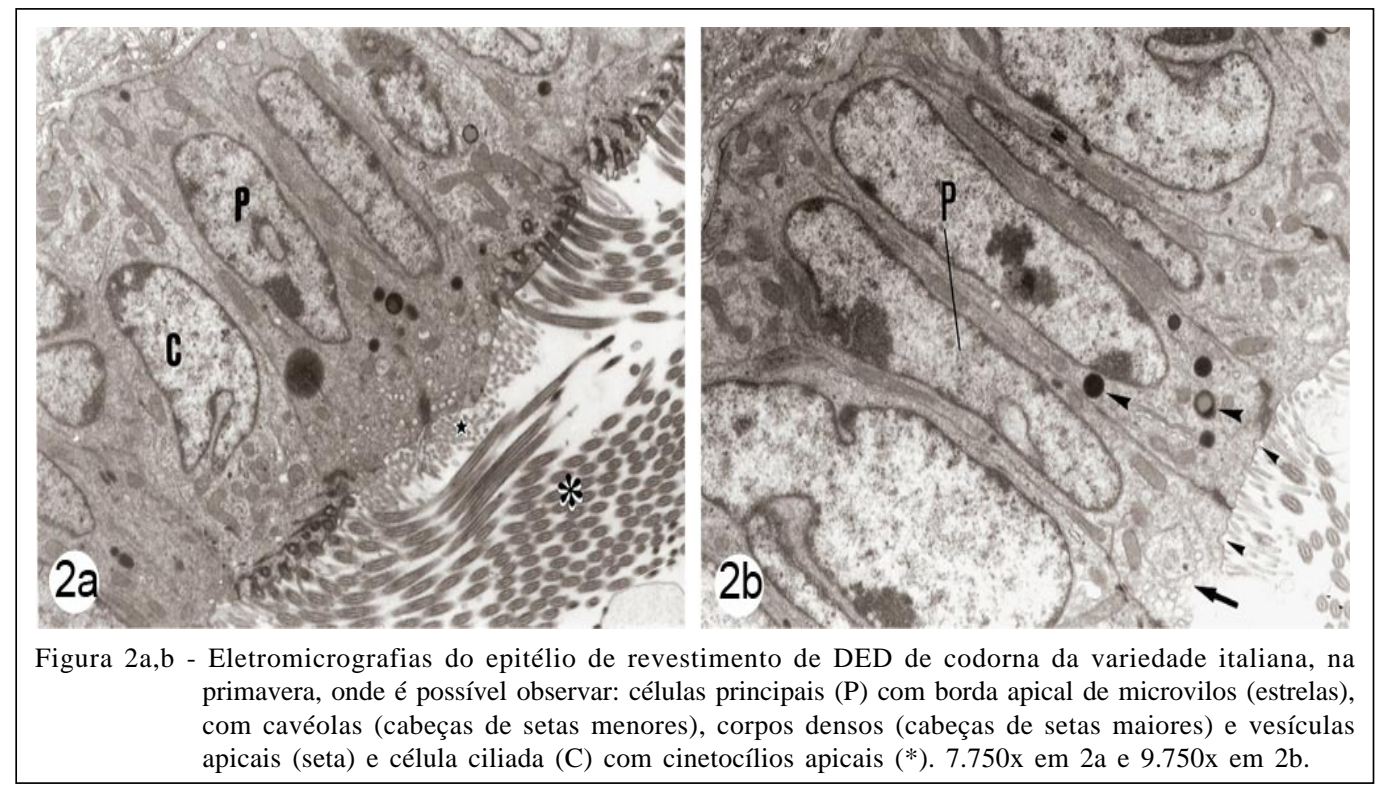

No outono, tanto nas células P (Figura 4a), como nas células $C$ (Figura 4b), verificou-se baixa eletrondensidade núcleo-citoplasmática, havendo em algumas células $P$ expansões do citoplasma supranuclear para o lúmen tubular, estando pouco nítidos os limites citoplasmáticos apicais. O lúmen tubular era ocupado por fluido seminal e remanescentes de cílios desprendidos do citoplasma apical de células C, não se notando também os microvilos das células $P$, desgarrados durante a retração citoplasmática apical
(Figura 4b). As organelas presentes nas células C e P, em quantidade relativamente menor que as observadas nos mesmos tipos celulares na primavera, foram mitocôndrias, lamelas do RE-granular, vesículas associadas e raros lisossomos. Foram observadas ainda características de degeneração no citoplasma supranuclear e apical, marcadas pela eletronlucência citoplasmática e desorganização de organelas citoplasmáticas (Figuras 4a, b).

Durante o inverno, no período recrudescente do ciclo testicular anual, as células C e P

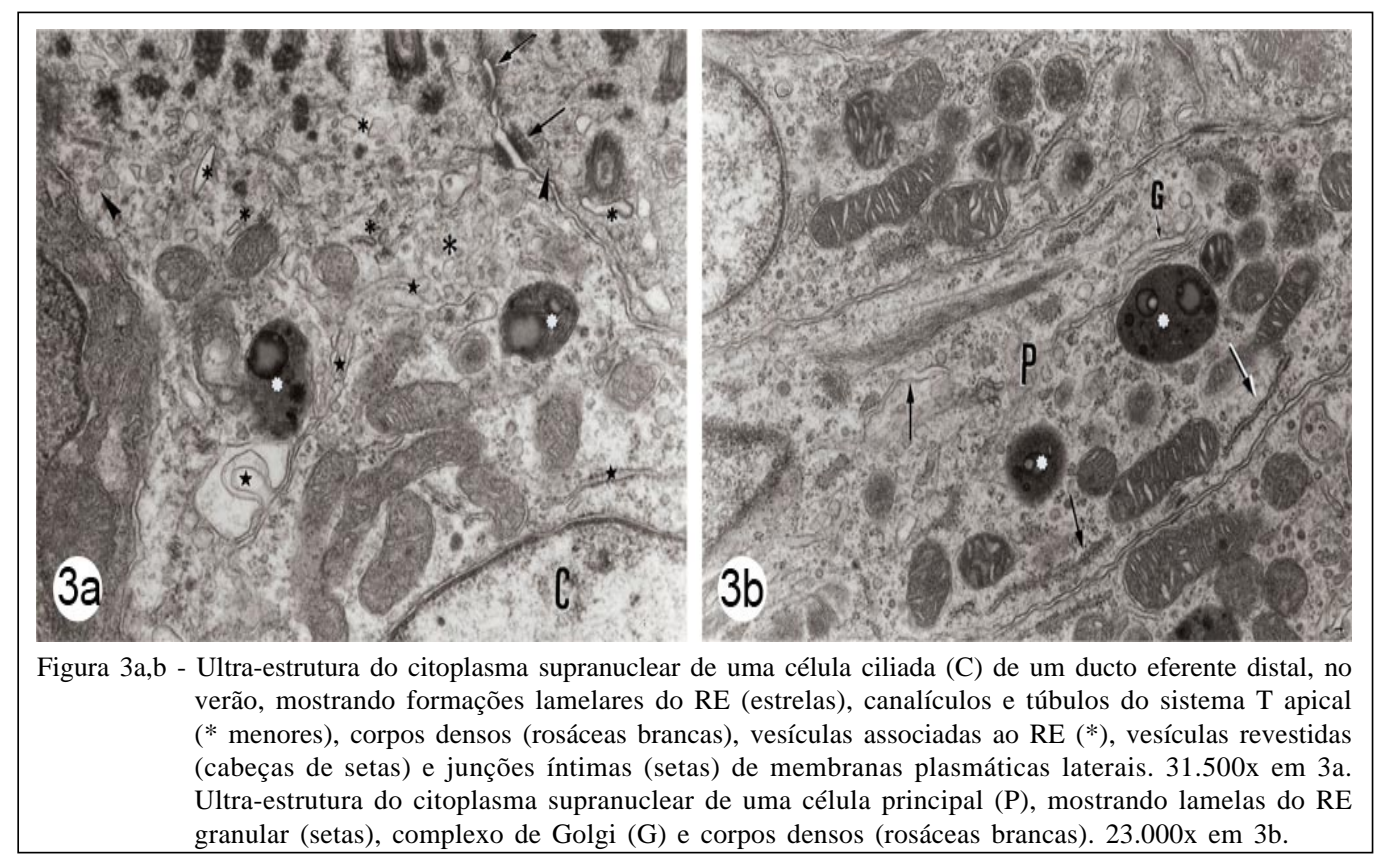

Ciência Rural, v.38, n.6, set, 2008. 


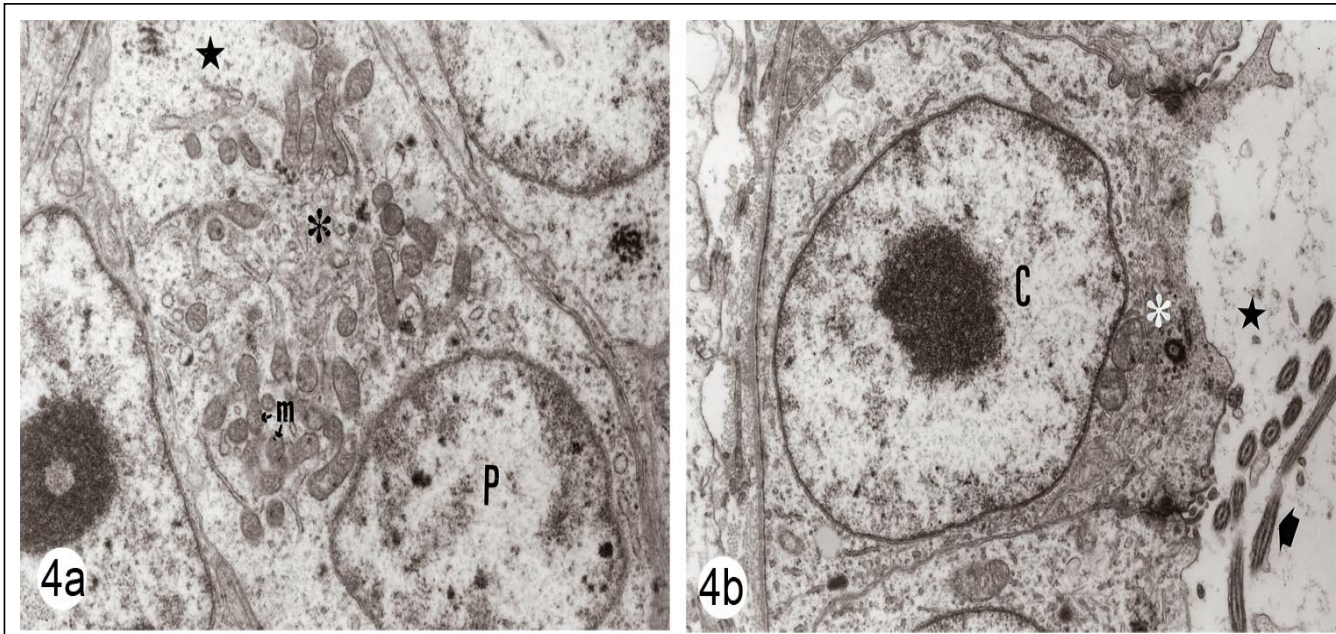

Figura 4a,b - Aspectos ultra-estruturais, com características de degeneração citoplasmática supranucleares $\left(^{*}\right)$ e apicais (estrelas) em ambas as células, desestruturação do RE (*) agregado de mitocôndrias atípicas no citoplasma supranuclear também eletrolucente; desgarramento de cílios (seta espessa), estreitamento do citoplasma supranuclear com pobreza de organelas. 13.250x.

pareceram recuperar as características ultra-estruturais básicas, observadas no mesmos tipos celulares de primavera (Figura 5a). No citoplasma apical de algumas células $\mathrm{P}$, no inverno, ocorreram expansões citoplasmáticas apicais, vistas junto à margem apical de microvilos, havendo corpos densos, com diferentes graus de compactação, associados à presença de microtúbulos, canalículos e vesículas revestidas por membrana, com conteúdo finamente granular (Figura 5b).

\section{DISCUSSÃO}

A margem apical de cinetocilios presente nas células ciliadas (C) dos DED, em codorna doméstica da variedade italiana, objetiva a ocorrência de movimentação ativa de fluido seminífero ao longo da luz dos ductos eferentes (DE) do testículo, como afirmaram anteriormente BELLAMY; KENDALL (1985) para o estorninho. No entanto, os cílios não são muito freqüentes em outros túbulos da região epididimária

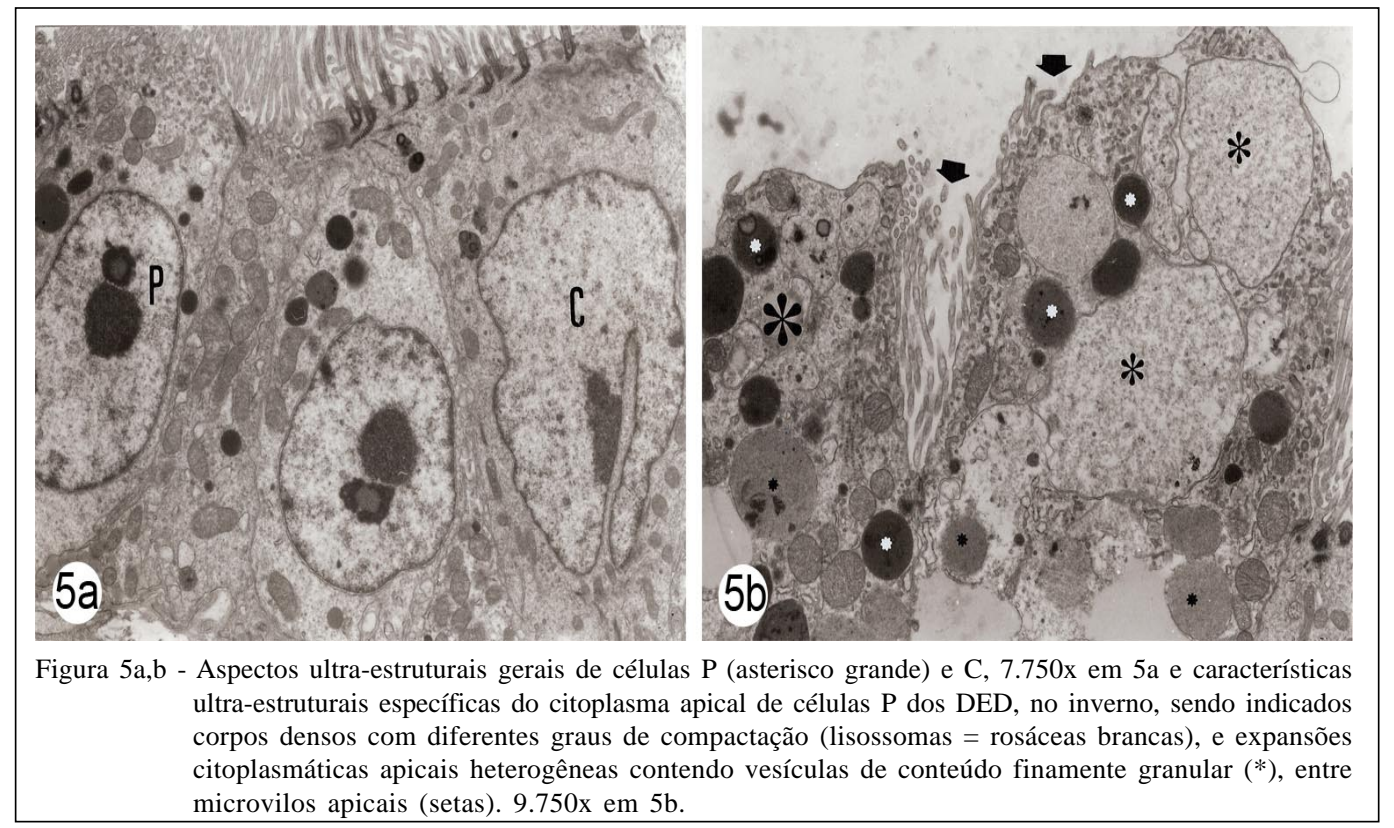

Ciência Rural, v.38, n.6, set, 2008. 
de aves (AIRE, 1980; 2000; 2002; STEFANINI et al., 1999a; BALDAN et al., 2003), onde o fluxo de fluidos parece ser menor (ORSI et al., 2007). Ainda quanto às células $\mathrm{C}$ dos $\mathrm{DE}$, no pombo, foi descrito um processo de ciliogênese ativa, com renovação ciliar permanente (STEFANINI et al., 1999a,b), observação que está de acordo com o presente estudo.

Células C, em codorna, mostraram configurações citoplasmáticas com vesículas eletrolucentes apicais e lisossomos e grande número de mitocôndrias apicais, características estas que as habilitam para realizar endocitose ativa (HERMO et al., 1994 - referência comparativa em DE nos mamíferos). Processos endocitóticos e reabsortivos se reservam mais às células principais $(\mathrm{P})$ ou nãociliadas (NC do tipo I, AIRE, 1979; OZEGBE et al., 2006), presentes nos DEP de aves. Suporta a endocitose a morfologia do sistema canaliculartubular citoplasmático apical e das vesículas a ele associadas, similarmente ao que se descreveu e discutiu nos DE do camundongo isogênico (ORSI et al., 1998) e nos DEP da própria codorna italiana (ORSI et al., 2007). Porém, não ocorreria endocitose nos DED de avestruz (OZEGBE et al., 2006), mas ocorre em células P dos DE em pombo (STEFANINI et al., 1999a) e aqui em codorna.

Observações feitas no inverno, nas células $P$ dos DEP (ORSI et al., 2007) e DED de codorna italiana, aqui enfocados, permitiram ver projeções citoplasmáticas apicais entrando na luz tubular, quando arrastam parte do citoplasma apical, sugerindo a ocorrência de secreção apócrina. Apoio para isso foi encontrado em observações similares, vistas em algumas células NC (P) da via extratesticular do peru (HESS; THURSTON, 1977), de aves ratitas (BUDRAS; MEIER, 1981), em células $P$ dos DE do pombo (STEFANINI et al., 1999a, b) e em células NC do ducto deferente do periquito australiano (BALDAN et al., 2003).

No outono, a fase quiescente do ciclo reprodutivo anual, as células $P$ e as células $C$, nos DEP (ORSI et al., 2007) e nos DED de codorna italiana, sofreram processos degenerativos típicos, caracterizados pela presença de grandes áreas citoplasmáticas apicais eletrolucentes. A luz tubular estava preenchida por material vacuolizado, remanescentes de cílios e microvilos, que se desprenderam dos citoplasmas apicais, e também possuíam alguns debridamentos celulares. Estas observações, resguardadas as peculiaridades espécieespecíficas, foram similares às descritas em células $\mathrm{P}$ dos DE epididimários do esquilo Citellus lateralis (Say) na etapa regressiva testicular daquela espécie
(PUDNEY; FAWCETT,1984). Entretanto, ressalta-se que nenhuma ausência de luz (ou colapso tubular) dos DED foi notada na codorna italiana durante a fase quiescente do ciclo, como fora caracterizada nesta etapa para o estorninho (BELLAMY; KENDALL, 1985).

As células epiteliais dos DED em codorna italiana, no inverno, mostraram maior número de lisossomos, com posição predominantemente supranuclear, e de expansões citoplasmáticas apicais, relativamente às outras estações do ano, já se discutindo, anteriormente, o significado das expansões citoplasmáticas. Quanto aos corpos densos, com características de lisossomos, eles não ocorreriam nas células NC do tipo II (AIRE,1979), conforme a própria classificação de Aire para as células P dos DE. Entretanto, na variedade italiana de codorna, os lisossomos foram observados nas células não ciliadas (P) de ambos os tipos de ductos excretores dos testículos, ou seja, nos DEP e DED.

\section{CONCLUSÕES}

Os valores médios de diâmetros tubular e luminal e aqueles de altura epitelial dos ductos eferentes distais (DED) em codorna da variedade italiana, associados às observações ultra-estruturais do epitélio de revestimento destes ductos, evidenciou um comportamento sazonal na morfologia dos DED, que se caracterizou por uma marcante, porém breve, quiescência outonal. Observações destes mesmos parâmetros, quantitativos ou qualitativos, nas outras estações do ano, mostraram padrões morfológicos similares nos DED na primavera, no verão e no inverno. Pequenas variações citoplasmáticas foram notadas na ultra-estrutura das células epiteliais dos ductos, permitindo estabelecer uma diferenciação cíclica, talvez semicíclica, na morfologia e na histofisiologia dos DED ao longo das estações do ano. Padrão semicíclico seria denotado pela quiescência outonal, pela aparente constância dos padrões morfométricos e citológicos tubulares nas outras três estações do ano. Estes seguiram um padrão similar de ciclagem testicular anual antes descrito (ORSI et al., 2005) para esta mesma espécie e nas mesmas condições de cativeiro experimental. Efetivamente, a morfologia e a cinética da via seminífera testicular e dos ductos excretores do testículo, no caso dos DED aqui enfocados, obedecem padrões morfológicos comuns e inter-relacionados.

\section{AGRADECIMENTOS}

Aos apoios financeiros concedidos para os estudos (Auxílios à Pesquisa), processos 30.1242/80 RN - CNPq, Brasília, Brasil e 03/00879-0 - FAPESP, São Paulo, Brasil.

Ciência Rural, v.38, n.6, set, 2008. 


\section{REFERÊNCIAS}

AIRE, T.A. The epididymal region of the Japanese quail (Coturnix coturnix japonica). Acta Anat, v.103, p.305-312, 1979.

AIRE, T.A. The ductuli efferentes of the epididymal region of birds. J Anat, v.130, p.707-723, 1980.

AIRE, T.A. Aspects of the functional morphology of the ductus epididymidis in domestic anseriform and galliform birds. Anat Histol Embryol, v.29, p.179-191, 2000.

AIRE, T.A. Cyclical reproductive changes in the non-ciliated epithelia of the epididymis of birds. Anat Histol Embryol, v.31, p.113-118, 2002

BALDAN, C. et al. Morphology of the vas deferens of the budgerigar (Melopsittacus undulatus). J Submicr Cytol Pathol, v.35, p.77-82, 2003.

BELLAMY, S.J.; KENDALL, M.D. The ultrastructure of the epithelium of the ductuli efferentes testis in the common starling (Sturnus vulgaris). J Anat, v.140, p.189-203, 1985.

BUDRAS, K.D.; MEIER, U. The epididymis and its the development in ratite birds (Ostrich, Emu, Rhea). Anat Embryol, v.162, p.281-299, 1981.

CLERMONT, Y. Introduction to the Sertoli cell. In: RUSSEL, L.; GRISWOOD, M.D. (Eds.). The sertoli cell. Clearwater, FL: Cache River, 1993. 801p.

HERMO, L. et al. Secretion and endocytosis in the male reproductive tract: a role in sperm maturation. Int Rev Cytol, v.154, p.105-189, 1994.
HESS, R.A.; THURSTON, R.J. Ultrastructure of the epitelial cells in the epididymal region of the turkey (Meleagris gallopavo). J Anat, v.124, p.765-778, 1977.

MORALES, C.R. et al. Endocytosis in epithelial cells linning the rete testis of the rat. Anat Rec, v.209, p.185-195, 1984.

MORRISON, D.F. Multivariate statistical methods. Tokio: Kogakusha, 1976. 415p.

ORSI, A.M. et al. Morphological investigations of the surface epithelium of ductuli efferentes of black isogenic mice (Mus musculus). Anat Histol Embryol, v.27, p.215-218, 1998.

ORSI, A.M. et al. Aspectos morfológicos do ciclo testicular anual de codorna doméstica (Coturnix coturnix) da variedade italiana. Braz J Vet Res Anim Sci, v.42, p.163-170, 2005.

ORSI, A.M. et al. Estrutura microscópica do complexo tubular rede testicular-ductos excretores proximais do testículo em codorna doméstica (Coturnix coturnix). Rev Vet Not, Uberlândia, no prelo, 2007.

OZEGBE, P.C. et al. The morphology of the efferent ducts of the testis of the ostrich, a primitive bird. Anat Embryol, v.211, p.559-565, 2006.

PUDNEY, J.; FAWCETT, D.W. Seasonal changes in fine structure of the ductuli efferentes of the ground squirrel, Citellus Iateralis (Say). Anat Rec, v.208, p.383-399, 1984.

STEFANINI, M.A. et al. Morphologic study of the efferent ductules of the pigeon (Columba livia). J Morphol, v.242, p.247-255, 1999a.

STEFANINI, M.A. et al. La región epididimaria de la paloma (Columba livia): análisis morfológico y morfométrico. Rev Chil Anat, v.17, p.21-25, 1999b. 